\title{
How to connect societal concerns on subsidence to expert knowledge
}

\author{
Ingrid C. Kroon ${ }^{1}$, Peter A. Fokker ${ }^{2}$, and Jaap N. Breunese ${ }^{1}$ \\ ${ }^{1}$ Advisory group for economic affairs, TNO, Utrecht, 3584 CB 6, the Netherlands \\ ${ }^{2}$ Applied geosciences, TNO, Utrecht, 3584 CB 6, the Netherlands \\ Correspondence: Ingrid C. Kroon (ingrid.kroon@tno.nl)
}

Published: 22 April 2020

\begin{abstract}
The proper management of subsidence hazards requires a procedure to formulate thresholds and measurement \& control loops. Such a formulation should be adequate in terms of technical hazard and hazard perception, unambiguous, in plain language and preferably complying with national or international standards. The technical nature of subsidence measurements, modeling and forecasts makes the important task of transferring knowledge on this issue from society to the research community and vice versa challenging. In this paper, we therefore propose a phased procedure of setting subsidence thresholds and control loops, intended for general use. The procedure is illustrated with three cases of mining projects from the Netherlands: gas production from fields below the Wadden Sea, salt production near Veendam, and gas production near Harlingen. We provide guidance for future use of the procedure and conclude with a few suggestions on the translation issue to the subsidence expert community.
\end{abstract}

\section{Introduction}

Subsidence and its many possible consequences is often cause for societal concerns. These have to be addressed by the project promotor or the competent authority, especially if the project activities proposed allow for the timing or amount of subsidence to be fully or partially controlled. For this, there are four options: (i) reassurance in case of negligible consequences, (ii) preventing or mitigating measures in case of manageable consequences, (iii) setting a subsidence threshold to ensure that the project activities are constrained such that the consequences are manageable, or (iv) - in case project adaptation is not or no longer technically or economically feasible - project abortion. Which option is applied is relevant for all stakeholders involved, whereas for the competent authority it poses a dilemma. A reliable way to partially overcome this dilemma is by guiding the decision using objective criteria. This requires a procedure to formulate thresholds and measurement \& control loops. The resulting formulation should be evidence based, technically adequate, preferably complying with national or international standards, unambiguous and in plain language. The first three aspects mainly relate to technical or juridical expertise, to be dealt with by subsidence experts and other specialists, whereas the last two aspects are mainly concerned with communication between the competent authority, the project promotor and local or regional stakeholders. This communication is challenging for several reasons: (i) the technical nature of subsidence measurements, modeling, forecasts and risk assessments, (ii) the many possible consequences of subsidence and the background expertise involved therein, and (iii) translation issues.

Trying to communicate our findings to others than our peers is something many of us experience in our daily work. As a community of subsidence experts we are regularly asked to contribute one way or another and some element of communication is always involved - though usually not all the way down to "plain language". In other words, the larger problem is how to transfer information, knowledge and perceptions from society to the research community and vice versa. This we will contemplate here, focusing mainly on the "role of the subsidence expert".

To identify this role more clearly we propose a phased procedure of setting subsidence thresholds and control loops. 
This procedure is intended to be of general use. It thus provides (i) a structure for the larger conversation, that is between project promotor, competent authority, stakeholders and experts, (ii) an overview of the available threshold types and (iii) a list of suggested technical questions. The procedure is illustrated with reference to three cases of mining projects from the Netherlands. We close this proposition by providing some guidance for future applications of the procedure and conclude with a few suggestions on the translation issue.

\section{A phased procedure and the role of subsidence experts}

In this section we propose a phased procedure of setting subsidence thresholds and measurement \& control loops and we discuss the role of the subsidence expert therein.

\subsection{Procedure}

The procedure consists of two basic elements: (i) assessing the project application provided by the project promotor and (ii) a decision process for setting respectively the threshold type, limit values and control loop. In this process alternatives are explored by the competent authority through stakeholder and expert consultation.

Assessing the project application:

0 . Starting point should be that the project promotor timely provides the competent authority and other stakeholders with information on the planned economic project that is expected to cause subsidence. This information of course is to be derived from the actual project plan, but summarized in a "user friendly" fashion, focusing on key parameters (nature, time, size, location) and possible environmental and societal effects.

1. The first step is to understand the societal concerns related to past, current and future subsidence in the area of interest. Comprehensive hearings of the stakeholders are therefore required. The findings should be combined, drafted in plain, intelligible language and double checked for unambiguous understanding. Stakeholders inform the competent authority on their preferred "subsidence threshold" adapted to local circumstances. Furthermore, agreements should be made on how to involve subsidence experts.

2. The second step involves the translation from "plain language" into "expert terminology". The translation should result in a set of "technical questions" to be agreed upon between the competent authority and the experts (see Appendix A for suggested questions). On a case-by-case basis technical questions depending on local circumstances should be added. Non-technical so-
Table 1. Overview of subsidence threshold types.

\begin{tabular}{lllll}
\hline Type & Area & Time & Limit & Unit \\
\hline A & local & static & max. deformation & $\mathrm{m}$ \\
\hline B & local & dynamic & $\begin{array}{l}\text { max. deformation } \\
\text { rate }\end{array}$ & $\mathrm{m} \mathrm{s}^{-1}$ \\
\hline C & regional & static & max. deformation & $\mathrm{m}$ \\
\hline D & regional & static & $\begin{array}{l}\text { max. averaged } \\
\text { deformation }\end{array}$ & $\mathrm{m}^{3} \mathrm{~m}^{-2}$ \\
& & & $\mathrm{~m}^{-1}$ \\
\hline E & regional & dynamic & $\begin{array}{l}\text { max. deformation } \\
\text { rate }\end{array}$ & $\mathrm{m} \mathrm{s}^{-1}$ \\
\hline F & regional & dynamic & $\begin{array}{l}\text { max. averaged } \\
\text { deformation rate }\end{array}$ & $\mathrm{m}^{3} \mathrm{~m}^{-2} \mathrm{~s}^{-1}$ \\
& & & $\mathrm{~m} \mathrm{~s}^{-1}$ \\
\hline
\end{tabular}

cietal concerns are listed and set aside until step 4 or 9.

After these three steps both the societal concerns and the relevant technical questions in relation to the project application have been listed.

The decision process for the threshold type:

3. The technical questions are assessed by the experts in an exploratory mode with the aim to identify relevant hazards and knowledge gaps and also providing a quick scan of the area's vulnerability to land subsidence. The experts should also check if the available information is likely to be technically sufficient for defining a measurement \& control loop (in steps 7-9). The experts should then come up with a proposal for the authority that details a set of fit-for-purpose types of "subsidence thresholds". A limited number of subsidence threshold types is available (Table 1).

4. Next, the competent authority verifies to what extent the proposal and its alternatives (step 1) allow for the underlying purposes to be reached: project (step 0), hazards (step 3) and non-technical societal concerns (step 2). This enables the competent authority to assess all the possibilities, weigh the pros and cons, and finally decide on the type of threshold. The authority informs the project promotor, stakeholders and experts on the chosen threshold type.

The decision process for the limit values:

5. Following step 4 "limit values" have to be established, including their justification. This justification usually requires the authority to ask experts to perform a more in-depth analysis on (some of) the technical questions of step 3. Based on their findings, the experts should then come up with a limit value proposal ensuring the conclusiveness of the chosen threshold type. 
6. Next, the competent authority consults the stakeholders on the non-technical societal concerns (step 2) related to the limit values proposed. We recommend to make a plain language summary of the findings up to now available (including non-technical issues) to the stakeholders. After consultation the authority has all the information required to formally set the limit values. The authority then informs the project promotor, stakeholders and experts on the chosen limit values.

Any threshold is set with the purpose to be maintained. Thus, a proper measurement $\&$ control loop allows for timely intervention, also in case of large uncertainties (cf. De Waal et al., 2017). It shows when and how to intervene based on measurements from monitoring, what the result of taking certain measures would be, and how this may be confirmed by monitoring.

The decision process for the measurement $\&$ control loop:

7. Using the available information from step 6 the experts should come up with a measurement \& control loop proposal. This is usually done by defining a control loop with a number of indicators and technically justified indicator limit values (sometimes called traffic lights) defining when to take specific technical measures. The proposal should be based on a probabilistic approach (thereby taking into account uncertainty) and it should describe the monitoring requirements and technical measures that need to be in place.

8. The authority should discuss the proposal with the project owner and check if a feasibility study is needed in addition to the information from step 0 . We recommend to make a plain language summary of the findings (including non-technical issues) available to the stakeholders.

9. The authority consults the stakeholders on the nontechnical concerns (step 2) in relation to the measurement \& control loop indicators proposed, possibly resulting in additional indicators to be formulated. It is recommended for the authority to check again with the project owner, if these indicators are feasible. After this consultation the competent authority has all the information required to formally set the control loop for the project. Once the measurement \& control loop has been decided on, the authority informs the project promotor, stakeholders and experts.

Having a control loop in place allows for an appropriate monitoring program to be established. The monitoring program should be divided into two parts, respectively (a) technical hazards and (b) societal concerns. This division may assist in avoiding misinterpretation between the experts and the stakeholders about the value of specific measurements in relation to intervention.

\subsection{Role of subsidence experts}

The phased procedure enables us to more clearly identify the role of subsidence experts. In step 1 of the procedure agreements on how to involve subsidence experts by either the competent authority, the project promotor or other stakeholders are made. In certain steps (2, 3, 5 and 7) subsidence expertise is required - mainly requiring experts to come up with proposals for setting subsidence thresholds and control loops and provide the scientific justification. Also in following stages the contribution of experts may be asked, for example to elucidate the justification to stakeholders or to court, review the argumentation of peers, or verify whether a subsidence threshold has been met. It is worth mentioning that the perspective of experts changes from looking at single projects to managing a national portfolio.

\section{Real world application}

Three cases from the Netherlands are used to illustrate real world application of the procedure, addressing aspects of procedure feasibility, threshold type application, limit value justification, monitoring and intervention. Please note that the large majority of mining projects in the Netherlands cause less than two $\mathrm{cm}$ of subsidence over their lifetime. For illustration purposes, we have chosen three cases where subsidence did or does play a role. Case descriptions focus on the procedure and are not intended to be exhaustive with respect to societal concerns on subsidence. The Minister of Economic Affairs is the competent authority. Access to the national mining data repository of the Netherlands, as well as background technical information on the cases mentioned, is available through https://www.nlog.nl/ (last access: 20 February 2020; in English). License documents are provided at https://www.rijksoverheid.nl/ (last access: 20 February 2020; in Dutch). Reference levels and benchmarks are a regular part of setting a subsidence threshold, usually in relation to the limit value. In the Netherlands their usage is currently being scrutinized (Tcbb, 2018).

\subsection{Wadden Sea gas production}

This is a well-documented case (cf. Vermeersen et al., 2018; Fokker et al, 2018, and references therein) consisting of gas fields operated by NAM since 2006. In hindsight all steps in the procedure have been virtually complied with. Step 0 brought on a 14 year national public debate pointed at subsidence threatening ecological values. The technical work related to steps 2 and 3 took a couple of years, resulting in a "type F" threshold (De Waal et al., 2012) related to net sand budgets in tidal basins (step 4) and a number of limit values (step 6), some of which have to be periodically updated (i.e. local sea level rise scenarios are to be updated every five years). A measurement $\&$ control loop system was put in place (steps 7-9). Its indicators have a clear technical 
meaning in relation to predefined technical measures. To include the tidal basin an existing subsidence monitoring program was extended. Consultation of the stakeholders in the various steps resulted in an existing ecological monitoring system being extended and a sediment monitoring system being put in place. This illustrates how non-technical concerns may result in additional monitoring that is only loosely related to the subsidence threshold, but has a clear scientific purpose. To date, the original limit and indicator values remain unchanged apart from the regular updates. This illustrates that the procedure can result in a stable outcome - even in a case subject to a national debate and requiring a complicated threshold type. Stakeholders have repeatedly confronted the limit value justification with progressive insights in court, in particular concerning the sea level rise scenario's. This illustrates the capability of several stakeholders to challenge a technically complicated limit value justification with equally complex progressive insights.

\subsection{Veendam salt production}

This case (cf. Rondeel et al., 1996; Fokker and Kruse, 2002; Kroon et al., 2003) consists of several caverns that are currently being operated by Nedmag. The local water management system is sensitive to subsidence, which is limited by a "type C" threshold. A monitoring program for subsidence and cavern pressure conditions was put in place. At the start of production the forecasted long term subsidence for the area was deemed acceptable. In consultation with the local Water Board authority the process of setting limit values was brought in line with the water management program: necessary measures related to the salt subsidence were split into tranches. For each tranche the competent authority sets a subsidence limit value (steps 1 and 6) and each subsequent tranche warrants new permission (requiring step 6 to be repeated). As a result, limit values of the Veendam case have been raised in a stepwise fashion throughout the decades of its production history. This illustrates that the procedure is in principle capable of honoring local circumstances and stakeholders.

\subsection{Harlingen gas production}

This case is a gas field (Van den Bosch, 1983) with a "type C" threshold. As a result, the "deepest point of the subsidence bowl" estimated from the monitoring data largely determined the outcome of the control loop (step 9). During monitoring four measuring points from the regular leveling network near the deepest point showed faster than forecasted subsidence rates and were suspected to be "unstable". Using a complementary measurement technique (PS-InSAR; MuntendamBos et al., 2009), it became clear that the signal from these leveling points was indeed real - the likely result of pore collapse in the porous reservoir chalk (De Waal et al., 2016). Consequently, gas production by Vermilion was halted by the competent authority in 2008. This illustrates the close interplay between threshold type, limit values, subsidence forecast, monitoring requirements and intervention measures in the control loop. It also illustrates that subsidence forecasts may be associated with a large uncertainty.

\section{Discussion}

In this final section we discuss some implementation issues to be considered for application of the phased procedure, and we conclude with a few remarks on the translation issue.

The phased procedure is in principle feasible (see Sect. 3). Still, a number of issues must be kept in mind. For instance, one might think that the procedure efficiency were improved by combining two or three decision processes. However, such shortcuts are likely to reduce the larger conversation between project promotor, competent authority, stakeholders and experts at the crucial project application stage - thereby risking a narrow vision on subsidence thresholds and compromising stakeholder engagement.

A second issue is about possible gaps that stakeholders observe between sharing and receiving information. The information they receive from the subsidence experts concerns the "technical questions", whereas information on the societal concerns labelled as "non-technical" is missing. This "missing information" should - according to the procedure - be provided earlier or at the same time as the technical information by the competent authority.

The last issue is about securing the quality of the information transfer and dealing with the fact that pieces of information get lost over time. Thus, repeated sharing of the original justification in addition to new perspectives is key for long term stakeholder engagement.

The larger problem addressed in this document is how to transfer information, knowledge and perceptions from society to the research community and vice versa.

As a community of subsidence experts we practice this transfer - without being professional translators. Some argue that scientists should become better storytellers, as that will make us more effective in our communication, also with professional translators such as science journalists (cf. Schimel, 2012). It may also help to be more aware of human psychological hurdles in appreciating science findings and ways to circumvent them (Kenrick et al., 2018). But foremost, we should be more aware of our role as subsidence experts in formal procedures and be willing to commit ourselves to taking this role one step further into knowledge transfer. 


\section{Appendix A: Suggested technical questions}

\section{A1 Suggested technical questions related to the past}

Which monitoring networks have been in place? What are their main technical requirements? Did this substantially change over time? Based on the available monitoring information, what amount/rate of subsidence occurred in the area of interest? What is the expected uncertainty range in space and time? Did the monitoring networks deliver: did the subsidence forecast become a reality? What is reported about the cause(s) of deviations from the forecast? Did the subsidence stay within its predefined limits? Which damage states on objects in the area of interest have been reported? Do these reports confirm the realized subsidence amount/rate? What are the lessons learned in terms of monitoring requirements?

\section{A2 Suggested technical questions related to the present}

What is the geological setting in relation to subsidence? Which cause(s) of subsidence are currently present? What is the surface setting? At which amount/rate of subsidence is the area vulnerable for subsidence hazards? Are there specific objects with a particularly high vulnerability for subsidence effects? If so, what are their main technical requirements?

\section{A3 Suggested technical questions related to the future}

Which cause(s) of subsidence are likely to be relevant in the next decades? How well are they understood? Is there a dominant source of subsidence to be expected? What is the forecasted "business as usual" subsidence? What amount/rate of subsidence is expected for the project? What is the expected uncertainty range in space and time? Is the forecast probabilistic? Could there be interference? Which monitoring requirements need to be in place to check the forecast? Are these requirements already met by existing monitoring networks? Is it feasible to disentangle between various causes? What measures are available for prevention or mitigation? Which surface developments may influence the subsidence hazard? 
Data availability. No data sets were used in this article.

Author contributions. ICK conceived the idea of this article and wrote it. PAF and JNB contributed to the development of the ideas and edited the text.

Competing interests. The authors declare that they have no conflict of interest.

Special issue statement. This article is part of the special issue "TISOLS: the Tenth International Symposium On Land Subsidence - living with subsidence". It is a result of the Tenth International Symposium on Land Subsidence, Delft, the Netherlands, 17-21 May 2021.

\section{References}

De Waal, J. A., Roest, J. P. A., Fokker, P. A., Kroon, I. C., Breunese, J. N., Muntendam-Bos, A. G., Oost, A., and Van Wirdum, G.: The effective subsidence capacity concept: how to assure that subsidence in the Wadden Sea remains within defined limits?, Neth. J. Geosci., 91, 385-399, https://doi.org/10.1017/S0016774600000512, 2012.

De Waal, J. A., Muntendam-Bos, A. G., and Van Thienen-Visser, K.: Lessons from larger than expected subsidence due to production of halite and natural gas in Fryslân, American Rock Mechanics Association, Houston, USA, no. 434, 2016.

De Waal, J. A., Muntendam-Bos, A. G., and Roest, J. P. A.: From checking deterministic predictions to probabilities, scenarios and control loops for regulatory supervision, Neth. J. Geosci., 96, s17-s25, https://doi.org/10.1017/njg.2017.15, 2017.
Fokker, P. A. and Kruse, G. A. M.: Salt deformation and subsidence, in: Learned and applied soil mechanics out of Delft, edited by: Barends, F. B. J., and Steijger, P. M. P. C., Zwets \& Zeitlinger B. V., Lisse, the Netherlands, ISBN 9058083573, 2002.

Fokker, P. A., van Leijen, F. J., Orlic, B., van der Marel, H., and Hanssen, R. F.: Subsidence in the Dutch Wadden Sea, Neth. J. Geosci., 97, 129-181, 2018.

Kenrick, D. T., Cohen, A. B., Neuberg, S. L., and Cialdini, R. B.: The science of anti-science thinking, Sci. Am., 319, 28-33, 2018.

Kroon, I. C., Orlic, B., and Scheffers, B. C.: Abandonment of solution mined salt caverns in the Netherlands, TNO, Utrecht, the Netherlands, NITG 03-172-B, 2003.

Muntendam-Bos, A. G., Hanssen, R. F., Van Thienen-Visser, K., and Esfahany, S.: PS-InSAR-analyse van de bodemdaling in Noordwest-Friesland, TNO, Utrecht, the Netherlands, TNO-034UT-2009-02318/A, 2009 (in Dutch).

Rondeel, H. E., Batjes, D. A. J., and Nieuwenhuijs, W. H.: Geology of gas \& oil under the Netherlands, The royal geological and mining society of the Netherlands KNGMG, Kluwer Academic Publishers, https://doi.org/10.1007/978-94-009-0121-6, 1996.

Schimel, J.: Writing science. How to write papers that get cited and proposals that get funded, Oxford University Press, Oxford, UK, 2012.

Technische Commissie bodembeweging (Tcbb): Representatieve nulmeting aan gebouwen, Kenmerk Tcbb 18236399, available at: https://www.tcbb.nl/file/download/57087387/ DOMUS-18236399-v5-22082018_Nulmeting_EZK.pdf (last access: 20 February 2020), 2018 (in Dutch).

Van den Bosch, W. J.: The Harlingen Field, the only gas field in the Upper Cretaceous Chalk of the Netherlands, in: Petroleum Geology of the Southeastern North Sea and the Adjacent Onshore Areas, Springer, Dordrecht, the Netherlands, 145-156, 1983.

Vermeersen, B., Fokker, P. A., Wang, Z. B., and Van der Spek, A. (Eds.): Sea-level rise, subsidence and morphodynamics in the Dutch Wadden Sea; 2030, 2050, 2100, Neth. J. Geosci., 97, 69214, https://doi.org/10.1017/njg.2018.7, 2018. 